\title{
(6) OPEN ACCESS \\ Relationship between knowledge about the harms of smoking and smoking status in the 2010 Global Adult Tobacco China Survey
}

\author{
Hui G Cheng, ${ }^{1}$ Orla McBride, ${ }^{2}$ Michael R Phillips ${ }^{1,3}$
}

\begin{abstract}
'Shanghai Mental Health Center, Shanghai Jiao Tong University School of Medicine, Shanghai, China

${ }^{2}$ School of Psychology, University of Ulster, Londonderry, Northern Ireland ${ }^{3}$ Departments of Psychiatry and Global Health, Emory University, Atlanta, Georgia, USA
\end{abstract}

\section{Correspondence to} Dr Hui G Cheng, Shanghai Mental Health Center Shanghai Jiao Tong University School of Medicine, Room 208, Building 9, Suicide Research and Prevention Center, 3210 Humin Road Shanghai 201108, China; chengyaojin@yahoo.com

Received 23 May 2013 Revised 5 August 2013 Accepted 6 August 2013 Published Online First 29 August 2013

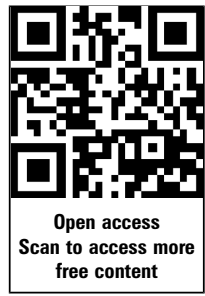

\section{CrossMark}

To cite: Cheng $\mathrm{HG}$ McBride 0, Phillips MR. Tob Control 2015;24:54-61.

\begin{abstract}
Background This analysis estimates the association between smoking-related knowledge and smoking behaviour in a Chinese context. To identify the specific knowledge most directly related to smoking status, we used a novel latent variable analysis approach to adjust for the high correlations between different measures of knowledge about tobacco smoking.
\end{abstract}

Method Data are from the Global Adult Tobacco China Survey, a nationally representative sample of 13354 household-dwelling individuals 15 years of age or older. Multinomial logistic regressions estimated the association between smoking status (ie, never smoked, current smoker or past smoker) and four smoking-related beliefs: whether or not smoking causes lung cancer, heart attack and stroke, and whether or not low-tar cigarettes are less harmful. A latent variable approach reassessed these associations while taking into account the general level of knowledge about smoking.

Results After demographic variables and general knowledge about smoking had been controlled for, the belief that low-tar cigarettes are not less harmful was more prevalent in persons who had never smoked than in current smokers $(O R=1.3(95 \% \mathrm{Cl} 1.0$ to 1.7$)$ in men and $\mathrm{OR}=2.8(95 \% \mathrm{Cl} 1.3$ to 5.9$)$ in women); this association was even stronger when past smokers and current smokers were compared $(\mathrm{OR}=2.1(95 \% \mathrm{Cl} 1.5$ to 3.0$)$ in men and $\mathrm{OR}=5.0(95 \% \mathrm{Cl} 1.3$ to 20.1$)$ in women).

Conclusions Compared with those who have never smoked and those who have ceased smoking, current smokers in China are more likely to believe that low-tar cigarettes are less harmful than regular cigarettes.

\section{INTRODUCTION}

Tobacco smoking is one of the leading causes of disease burden around the globe. Based on current trends, it is estimated that tobacco smoking will account for 8.4 million premature deaths each year by 2020 (a 180\% increase from 1999). ${ }^{1}$ Projections from a recent nationally representative survey in China indicate that there are 301 million current smokers in China, $86 \%$ of whom are daily smokers with an average daily consumption of 14.2 cigarettes. $^{2}$ Awareness of the urgent need to stem the smoking epidemic in China has resulted in several anti-smoking regulations and many regional and national anti-smoking campaigns since the mid-1980s. However, these efforts have had relatively little effect. Smoking is still prevalent in men$53 \%$ of adult men are current smokers-and only $15 \%$ of smokers quit smoking. ${ }^{2}$ Smoking cessation rates in China were the lowest among the 17 high- and low-to-middle-income countries considered in a recent multi-national study. ${ }^{3}$ Clearly, smoking remains a serious threat to health in China, and current anti-smoking educational programmes need to be made more effective.

The Chinese culture discourages female smoking; women who smoke are stigmatised because smoking is contrary to the expectations of the traditionally strong family-oriented social roles for women. Thus, a prominent feature of smoking in China is the substantial male/female difference in the rates of smoking. For example, the male/female ratio of smoking is 22 in the recent nationally representative survey, ${ }^{2}$ and the aforementioned multi-country study reported a 10-fold male/female difference in smoking in China, one of the largest among the 17 countries in the study. ${ }^{3}$ The latter study used data from two metropolitan cities in China; the relatively small male/female difference in this study compared with the nationally representative study may reflect the higher acceptance of female smoking in large cities. China is undergoing a rapid urbanisation process, so preventing the initiation of smoking by women is a current focus of preventive efforts.

Knowledge about the harms of smoking is a key element for smoking cessation and prevention. According to the knowledge-attitude-practice model, ${ }^{4}$ change in behaviour involves acquiring relevant knowledge, changing related attitudes and, finally, altering practices. However, studies from China have found only weak associations between knowledge about smoking and actual smoking behaviour. Studies from Western countries report that ex-smokers are twice as likely as current smokers to be aware of the harms of tobacco smoking, ${ }^{5}{ }^{6}$ but similar studies in China find a much weaker (or nonexistent) relationship between smoking status and knowledge of the health risks of smoking. ${ }^{7}-{ }^{10}$ The aforementioned 2010 national study in China ${ }^{2}$ found that $80 \%$ of smokers acknowledged smoking as a cause of lung cancer, which is similar to the proportion among smokers in the USA and other highincome countries. ${ }^{56}$ Despite the similarity in the level of awareness about the health risks of smoking, the proportion of smokers who stop smoking in China $(15 \%)^{11}$ is only one-third of the corresponding proportion in high-income countries. Understanding the mechanisms underlying this disconnect between awareness of the risks of smoking and smoking behaviour in China (and other low- and middle-income countries) could provide new targets for public health education campaigns.

There are some gaps in previous studies about the relationship between knowledge and smoking 
behaviour. First, many studies are conducted in specific subgroups (eg, health providers, students or military personnel), so their results may not apply to the general population, where the vast majority of smoking-related disease burden resides. To the best of our knowledge, there have been no nationally representative studies that focused on the relationship between knowledge about the health risks of smoking and smoking behaviour in China.

Second, previous studies usually limited their reports to the results from univariate analyses. ${ }^{12}{ }^{13}$ Failure to consider the many potential confounders by using multvariate techniques may lead to biased estimates of the real relationship between behaviour and knowledge. For example, low levels of education, 'blue collar' occupations and unemployment are associated with both smoking ${ }^{14}{ }^{16}$ and lower levels of knowledge about the harms of smoking. ${ }^{10} 1718$ It would be valuable to determine the extent to which the observed associations between smoking status and level of knowledge about the harms of smoking can be attributed to differential distributions of these demographic characteristics. Conversely, it would also be of value to assess the association between these demographic characteristics and smoking behaviour while keeping the level of knowledge about the harms of smoking constant- that is, an unconfounded assessment of the relationship of gender, age, educational level and occupation to smoking status. Information provided by these types of multivariate analyses would be of use in developing and testing targeted intervention strategies.

Third, various types of knowledge about smoking are intercorrelated. For example, individuals who identify smoking as a cause of lung cancer are more likely to identify smoking as a cause of heart disease than those who do not know smoking is a cause of lung cancer. Using standard multivariate logistic regression, estimates of the relationship of smoking behaviour to a single indicator (eg, knowledge about the risk of heart disease in smokers) may be inflated because of this intercorrelation. ${ }^{12} 131920$ Some studies use an overall knowledge score (typically by summing up all items) to deal with this issue, but this makes it impossible to identify the independent effects of specific items of knowledge and, moreover, assumes that there is a linear relationship between the knowledge score and smoking behaviour ${ }^{89}$ without inspecting the nature of the relationship. A clear understanding of the relationship between specific items of knowledge and the initiation or cessation of smoking requires the use of techniques that adjust for the intercorrelations between different items of knowledge; this can be accomplished by constructing latent variables that, when inserted in the models, adjust the analysis for the general level of knowledge about smoking. ${ }^{21}$

Finally, low-tar cigarettes have been promoted heavily as a 'less harmful' alternative to regular cigarettes. Numerous studies have found that this claim is false because smokers typically consume more to achieve the same effect. ${ }^{22}$ This misconception, perpetuated by the tobacco companies, may be one factor that makes it harder to quit smoking. There has been no study in China that has assessed the relationship between knowledge about low-tar cigarettes and smoking initiation or cessation.

To address these issues, this study uses both the traditional method (multivariate logistic regression) and a structural equation modelling (SEM) method to estimate the association between smoking behaviour and specific items of knowledge about the harms of smoking after adjustment for demographic factors and (in the SEM analysis) general knowledge about smoking by analysing data from a nationally representative sample of residents of China 15 years of age and above.
METHODS

\section{Sample}

The Global Adult Tobacco Survey (GATS), coordinated by the WHO, was jointly conducted in 14 countries using a standardised protocol. Data used in the current analysis are from GATS China (2010), which is a cross-sectional survey of non-institutionalised individuals who were at least 15 years of age. These deidentified data are publicly available at http://nccd.cdc.gov/GTSSData/ default/default.aspx. A multistage stratified cluster-sampling approach was used to ensure the representativeness of the sample. In brief, the sample selection started with dividing China into six geological regions (North, Northeast, East, Central and South, Southwest and Northwest), and then the six regions were further stratified into urban and rural areas resulting in 12 strata. In the first stage of sampling, urban districts or rural counties (primary sampling units) were selected using a probability proportionate to size method within each stratum. During the second stage of sampling, two urban neighbourhood communities or rural villages were selected from each primary sampling unit using the probability proportionate to size method. In each selected urban community or rural village, random sampling was used to select one block (of approximately 1000 households) and then 75 households within the block. During the last stage, one eligible individual from each household was selected using simple random sampling. This sampling strategy resulted in a total of 13562 individuals, of whom 13354 (98.5\%) completed the interview. The GATS interviews took place in participants' homes and were administered by trained interviewers. More details are available from the GATS China country report. ${ }^{23}$

\section{Assessments}

All individuals were categorised into three mutually exclusive groups: never smokers, current smokers and past smokers. Current smokers were defined as individuals who reported smoking any tobacco product currently; past smokers were defined as those who reported smoking any tobacco product in the past but not currently. Three separate questions about diseases caused by smoking were used to derive the first three indicators of smoking-related knowledge: 'Based on what you know or believe, does smoking tobacco cause lung cancer/stroke/heart attacks?'. Respondents who answered 'yes' for any of the three questions were coded as 1 on that item, and those who answered 'no' or 'do not know' were coded as 0 . An additional indicator of knowledge was whether the participant believed that low-tar cigarettes were less harmful than regular cigarettes ('no' $=1$, 'yes'/'do not know' $=0$ ). Therefore, the coding of ' 1 ' represents having the correct knowledge about smoking. All variables were based on self-report information. There were three respondents who had missing values for the first three knowledge variables and 25 respondents had missing values for the last knowledge variable.

Demographic covariates included gender, age, educational attainment (primary school or lower, middle school, high school, or college and above), urban or rural residence, and occupation (farmer, worker or soldier, office worker, student, doctor or teacher, unemployed, or retired). There were five respondents who had missing values on educational attainment, and 15 on occupation.

\section{Analysis}

Descriptive statistics of the demographic characteristics and responses to the four items about smoking knowledge were 
estimated for individuals classified in the three smoking categories (never, current and past smoker).

In the first set of estimations, bivariate and multivariate multinomial logistic regressions were used to estimate the association between smoking status, demographic characteristics and smoking-related knowledge. In these multinomial logistic regression models, the comparison category was the 'current smoker' category. Estimates comparing 'never smokers' with 'past smokers' were calculated using post-estimation linear combinations (ie, the 'lincom' command in Stata). All four knowledge items and all demographic variables were included in the multivariate regression models. ORs were used to represent the strength of associations.

Owing to concerns about the violation of the independent error term assumption of the general linear model, an SEM approach was used to serve as a post-estimation check. This approach started with a confirmatory factor analysis (CFA) to assess the unidimensionality of the four knowledge variables. The assumption of CFA is that the latent 'level of knowledge' gives rise to all four observed variables of knowledge. ${ }^{24}$ The construction of this latent variable reduces measurement error $^{24-26}$ and takes into account the intercorrelation between knowledge variables; this results in unbiased estimates when covariates are correlated or jointly determined ${ }^{24-26}$ - which is definitely the case for knowledge about the dangers of smoking. Indices for the goodness of fit of the CFA model included Root Mean Square Error of Approximation (RMSEA), Comparative Fit Index (CFI) and Tucker-Lewis Index (TLI). The RMSEA measures how well the model would fit the population covariance matrix. The CFI and TLI compare the proposed model with the null model (where there is no correlation). A value $<0.05$ for RMSEA and a value $>0.95$ for CFI and TLI are considered to indicate good fit. ${ }^{24-26}$

Subsequent to the CFA, four separate backward multiple indicator/multiple cause (MIMIC) models ${ }^{27}$ were built to estimate the association of each of the four specific knowledge variables with smoking status while keeping the general knowledge level about the health risks of smoking constant (see figure 1 for a depiction of the model used to assess the relationship of knowledge about low-tar cigarettes to smoking behaviour). In these models the 'latent knowledge' variable (constructed using the
CFA) takes care of the intercorrelation between all four knowledge variables, while the direct path in each of the models assesses the residual association between the specific knowledge item and smoking status. Demographic variables were included in the backward MIMIC models, and all analyses were conducted separately for men and women.

Possible clustering and design factors were taken into account using Taylor series linearisation. Probability weights were used to adjust for differential selection probability and non-response patterns. Post-stratification factors were used to bring the sample into balance with the source population with respect to region, residence, sex and age. ${ }^{29}$ The precision of estimates was gauged via 95\% CIs. Stata (V.11.2) and Mplus (V.6.12) statistical software were used for data analysis. A maximum likelihood estimator with robust SEs was used for the SEM models.

\section{RESULTS}

Most respondents knew that smoking causes lung cancer (varying from a low of $53.7 \%$ in female current smokers to a high of $84.7 \%$ in male never smokers). Less than half of the respondents knew that smoking causes heart attacks and stroke, ranging from $21.4 \%$ for stroke in female past smokers to $48.0 \%$ for heart attacks in male past smokers. Less than one-quarter of the respondents knew that low-tar cigarettes were not less harmful than regular cigarettes (varying from 3.6\% in female current smokers to $21.2 \%$ in male past smokers) (table 1 ).

Tables 2 and 3 show the results of both the unadjusted and adjusted multinomial logistic regression analyses. In almost all cases, men who had never smoked and those who had ceased smoking were more likely to give the correct responses to the four knowledge items than current male smokers, and men who had ceased smoking were more likely to provide correct responses than those who never started smoking. Most of these differences were statistically significant in the bivariate analyses, but only the differences in knowledge about low-tar cigarettes remained significant after adjustment for all variables in the model. In women, the bivariate analyses show that those who had never smoked or who had ceased smoking were also more likely to have the correct knowledge about the health risks of smoking than current smokers. After adjustment for the other variables in the model, the belief that smoking causes stroke was
Figure 1 Depiction of the structural equation model that assesses the relationship of knowledge about low-tar cigarettes while using a latent variable to adjust for general knowledge about smoking.

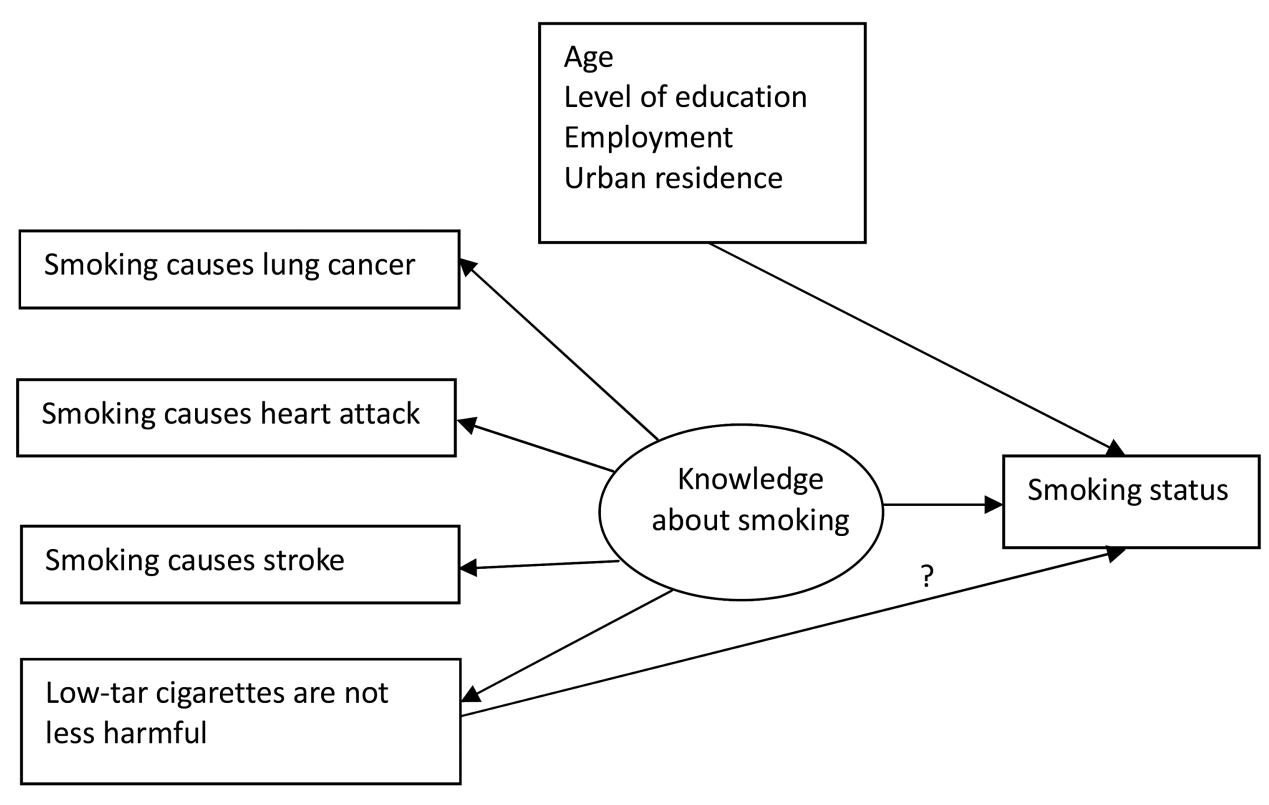

Cheng HG, et al. Tob Control 2015;24:54-61. doi:10.1136/tobaccocontrol-2013-051163 
Table 1 Weighted percentage of demographic variables and knowledge about tobacco smoking among male and female respondents to the GATS China ( $n=13$ 354) who reported that they had never smoked, were current smokers, or were past smokers

\begin{tabular}{|c|c|c|c|c|c|c|c|c|c|c|c|c|}
\hline \multirow[b]{3}{*}{ Variable } & \multicolumn{6}{|c|}{ Male $(n=6603)$} & \multicolumn{6}{|c|}{ Female $(n=6751)$} \\
\hline & \multicolumn{2}{|c|}{ Never smoked } & \multicolumn{2}{|c|}{$\begin{array}{l}\text { Current } \\
\text { smokers }\end{array}$} & \multicolumn{2}{|c|}{ Past smokers } & \multicolumn{2}{|c|}{ Never smoked } & \multicolumn{2}{|c|}{$\begin{array}{l}\text { Current } \\
\text { smokers }\end{array}$} & \multicolumn{2}{|c|}{ Past smokers } \\
\hline & $\mathrm{n}$ & $\%$ & $\mathrm{n}$ & $\%$ & $\mathrm{n}$ & $\%$ & $\mathrm{n}$ & $\%$ & $\mathrm{n}$ & $\%$ & $\mathrm{n}$ & $\%$ \\
\hline All respondents & 2045 & 37.2 & 3772 & 52.9 & 785 & 9.9 & 6438 & 96.9 & 238 & 2.4 & 71 & 0.7 \\
\hline \multicolumn{13}{|l|}{ Knowledge about smoking } \\
\hline Smoking causes lung cancer & 1637 & 84.4 & 2649 & 75.0 & 609 & 79.3 & 4700 & 76.6 & 125 & 53.7 & 41 & 63.6 \\
\hline Smoking causes heart attack & 916 & 46.2 & 1271 & 35.2 & 363 & 48.0 & 2393 & 36.9 & 69 & 24.6 & 27 & 42.0 \\
\hline Smoking causes stroke & 637 & 31.9 & 896 & 24.5 & 246 & 33.5 & 1654 & 26.3 & 57 & 21.8 & 16 & 21.4 \\
\hline Low-tar cigarettes no less harmful & 380 & 18.2 & 434 & 11.0 & 151 & 21.2 & 849 & 13.4 & 10 & 3.6 & 9 & 15.8 \\
\hline Urban residence & 1050 & 33.9 & 1723 & 29.7 & 365 & 34.6 & 3198 & 31.9 & 110 & 31.7 & 37 & 46.8 \\
\hline \multicolumn{13}{|l|}{ Level of education } \\
\hline No formal education & 124 & 2.3 & 232 & 3.5 & 66 & 6.5 & 1197 & 13.0 & 79 & 26.9 & 26 & 38.1 \\
\hline Primary & 370 & 12.4 & 996 & 18.5 & 255 & 27.2 & 1574 & 20.8 & 89 & 32.5 & 25 & 32.0 \\
\hline Secondary & 730 & 41.0 & 1544 & 44.9 & 238 & 31.9 & 2072 & 36.4 & 43 & 24.1 & 12 & 16.8 \\
\hline High school & 456 & 25.8 & 655 & 23.2 & 150 & 25.0 & 961 & 18.4 & 17 & 10.7 & 5 & 8.3 \\
\hline College & 364 & 18.6 & 345 & 10.0 & 74 & 9.4 & 637 & 11.5 & 10 & 5.9 & 3 & 4.8 \\
\hline \multicolumn{13}{|l|}{ Employment } \\
\hline Farmer & 633 & 23.8 & 1638 & 24.2 & 289 & 30.8 & 2672 & 33.2 & 119 & 41.2 & 28 & 31.1 \\
\hline Worker/soldier & 501 & 26.0 & 1127 & 37.5 & 135 & 19.7 & 1182 & 22.0 & 22 & 12.2 & 6 & 11.5 \\
\hline Office & 326 & 15.5 & 503 & 15.2 & 83 & 11.2 & 458 & 7.4 & 8 & 7.2 & 1 & 1.1 \\
\hline Doctor/teacher & 79 & 3.5 & 67 & 1.9 & 19 & 2.9 & 214 & 4.0 & 0 & 0 & 0 & 0 \\
\hline Student & 177 & 18.5 & 7 & 0.2 & 4 & 3.4 & 160 & 5.6 & 2 & 2.1 & 0 & 0 \\
\hline Unemployed & 92 & 4.7 & 175 & 5.0 & 58 & 9.3 & 982 & 16.8 & 54 & 22.2 & 19 & 31.6 \\
\hline \multirow[t]{2}{*}{ Retired } & 236 & 8.1 & 253 & 6.1 & 197 & 22.7 & 764 & 11.0 & 33 & 15.1 & 16 & 21.6 \\
\hline & Mean & SD & Mean & SD & Mean & SD & Mean & SD & Mean & SD & Mean & SD \\
\hline Age & 44.4 & 18.5 & 48.4 & 14.1 & 57.4 & 15.0 & 47.1 & 16.2 & 56.8 & 15.0 & 63.8 & 16.7 \\
\hline
\end{tabular}

The reported frequencies are those obtained from the study, but the reported percentage values were adjusted by weighting the crude proportions in each gender by age group cohort and making adjustments for the non-response pattern in each cohort.

GATS, Global Adult Tobacco Survey.

more common in current female smokers than in women who had never smoked or had ceased smoking. Associations between smoking status and knowledge were stronger among women than men (as assessed by a product term of a knowledge variable and the sex variable) for knowledge about lung cancer and knowledge about low-tar cigarettes when never smokers were compared with current smokers, and for knowledge about stroke when past smokers were compared with current smokers (all p values $<0.05$ ).

Tables 2 and 3 also show the relationship of demographic variables to smoking status both before and after adjustment for the other variables in the model. In men, urban versus rural residence was not related to smoking status, but, in women, the adjusted analysis found that those who had ceased smoking were more likely to come from rural areas than those who had never started smoking. For both sexes, individuals who had ceased smoking were older than those who were current smokers, and current smokers were older than those who had never started smoking. For both men and women, the univariate analysis found that individuals who had never started smoking had a higher educational attainment than current smokers, and current smokers had a higher educational attainment than past smokers; however, after adjustment for age in the multivariate analysis, none of these differences were statistically significant. Type of employment was not significantly related to smoking status in women, but there were several significant occupationrelated findings for men. After adjustment for age, location of residence, educational attainment and the knowledge variables, men who had retired were significantly more likely to be nonsmokers than male farmers, and after adjustment for the other variables, unemployed men were more likely to have ceased smoking than male farmers.

The Spearman correlation coefficients across the four knowledge variables varied from 0.57 (for knowledge about heart attack and stroke) to 0.15 (for knowledge about stroke and low-tar cigarettes). Factor loadings for the latent knowledge variable were 0.846 for knowledge about stroke, 0.926 for knowledge about heart attack, 0.813 for knowledge about lung cancer, and 0.354 for knowledge about low-tar cigarettes. Common fit indices found good fit of the one-factor CFA model in this sample: $\mathrm{RMSEA}=0.011 ; \mathrm{CFI}=0.999$; $\mathrm{TLI}=0.997$; and $\chi^{2}(\mathrm{df})=5.14(2)(\mathrm{p}=0.077)$.

Table 4 presents results for one of the four separate backward MIMIC models. After adjustment for other variables in the model, the latent knowledge variable was weakly, but significantly, associated with the cessation of smoking in both sexes. Latent knowledge was also greater in those who had never smoked than in those who were current smokers. After adjustment for general knowledge about smoking using the latent knowledge variable, individuals who had ceased smoking were more likely than current smokers or never smokers to know that low-tar cigarettes were not less harmful than regular cigarettes. The results for the other variables in the model-age, education and employment-were essentially the same as those seen in the analysis that did not adjust for latent knowledge (tables 2 and 3); one exception was that unemployed men and male doctors and 
Table 2 Comparison of demographic characteristics and knowledge about tobacco smoking between individuals with different smoking status among 6603 male respondents to the GATS China survey

\begin{tabular}{|c|c|c|c|c|c|c|}
\hline \multirow{2}{*}{ Variable } & \multicolumn{2}{|c|}{ Never versus current smokers } & \multicolumn{2}{|c|}{ Past versus current smokers } & \multicolumn{2}{|c|}{ Past versus never smokers } \\
\hline & uOR $(95 \% \mathrm{Cl})$ & aOR $(95 \% \mathrm{Cl})$ & uOR $(95 \% \mathrm{Cl})$ & aOR $(95 \% \mathrm{Cl})$ & uOR $(95 \% \mathrm{Cl})$ & aOR $(95 \% \mathrm{Cl})$ \\
\hline \multicolumn{7}{|l|}{ Knowledge } \\
\hline Smoking causes lung cancer & $1.8(1.4$ to 2.3$)$ & $1.2(0.9$ to 1.5$)$ & $1.3(0.9$ to 1.8$)$ & $1.3(0.9$ to 1.9$)$ & $0.7(0.5$ to 1.0$)$ & $1.1(0.7$ to 1.7$)$ \\
\hline Smoking causes heart attack & $1.6(1.3$ to 1.9$)$ & $1.2(1.0$ to 1.5$)$ & 1.7 (1.3 to 2.2 ) & $1.4(0.9$ to 2.1$)$ & $1.1(0.8$ to 1.5$)$ & $1.2(0.7$ to 1.8$)$ \\
\hline Smoking causes stroke & $1.4(1.2$ to 1.8$)$ & $1.1(0.8$ to 1.4$)$ & $1.5(1.1$ to 2.1$)$ & $1.1(0.7$ to 1.6$)$ & $1.1(0.8$ to 1.4$)$ & $1.0(0.7$ to 1.5$)$ \\
\hline Low-tar cigarettes not less harmful & $1.8(1.4$ to 2.3$)$ & $1.3(1.0$ to 1.8$)$ & $2.2(1.5$ to 3.1$)$ & $2.2(1.5$ to 3.2$)$ & $1.2(0.8$ to 1.7$)$ & $1.6(1.1$ to 2.3$)$ \\
\hline Urban residence & $0.8(0.7$ to 1.0$)$ & $1.0(0.8$ to 1.3$)$ & $0.8(0.6$ to 1.1$)$ & $1.1(0.7$ to 1.6$)$ & $1.0(0.7$ to 1.4$)$ & $1.1(0.7$ to 1.7$)$ \\
\hline \multicolumn{7}{|l|}{ Level of education } \\
\hline No education & 1.0 & 1.0 & 1.0 & 1.0 & 1.0 & 1.0 \\
\hline Primary & $1.0(0.7$ to 1.6$)$ & $0.8(0.5$ to 1.4$)$ & $0.8(0.5$ to 1.2$)$ & $1.2(0.8$ to 1.7$)$ & $0.8(0.4$ to 1.4$)$ & $1.5(0.7$ to 2.9$)$ \\
\hline Secondary & 1.4 (0.9 to 2.1$)$ & 0.7 (0.4 to 1.2$)$ & $0.4(0.2$ to 0.6$)$ & $0.8(0.5$ to 1.4$)$ & $0.3(0.1$ to 0.5$)$ & $1.1(0.5$ to 2.5$)$ \\
\hline High school & 1.7 (1.1 to 2.7$)$ & $0.6(0.4$ to 1.1$)$ & $0.6(0.4$ to 0.9$)$ & $1.0(0.6$ to 1.7$)$ & $0.3(0.2$ to 0.6$)$ & $1.6(0.7$ to 3.4$)$ \\
\hline College & $2.9(1.7$ to 4.8$)$ & $1.2(0.6$ to 2.3$)$ & $0.5(0.3$ to 0.9$)$ & $0.9(0.4$ to 1.7$)$ & $0.2(0.1$ to 0.3$)$ & $0.7(0.3$ to 1.7$)$ \\
\hline \multicolumn{7}{|l|}{ Employment } \\
\hline Farmer & 1.0 & 1.0 & 1.0 & 1.0 & 1.0 & 1.0 \\
\hline Factory worker/soldier & $1.0(0.8$ to 1.3$)$ & $0.8(0.6$ to 1.1$)$ & $0.6(0.4$ to 0.9$)$ & $0.8(0.5$ to 1.3$)$ & $0.6(0.4$ to 0.9$)$ & $1.0(0.6$ to 1.5$)$ \\
\hline Office worker & $1.5(1.1$ to 2.0$)$ & $1.0(0.7$ to 1.5$)$ & $0.8(0.5$ to 1.3$)$ & $0.9(0.5$ to 1.7$)$ & $0.6(0.4$ to 0.8$)$ & $0.9(0.6$ to 1.5$)$ \\
\hline Doctor/teacher & 2.7 (1.5 to 4.6$)$ & $1.7(0.9$ to 3.2$)$ & 1.7 (0.8 to 3.5$)$ & $1.4(0.6$ to 3.3$)$ & $0.6(0.3$ to 1.3$)$ & $0.8(0.4$ to 1.8$)$ \\
\hline Unemployed & $1.4(0.9$ to 1.9$)$ & $1.2(0.8$ to 1.7$)$ & 2.1 (1.3 to 3.2 ) & 2.3 (1.4 to 3.6$)$ & 1.5 (1.0 to 2.4$)$ & 1.9 (1.2 to 3.2$)$ \\
\hline Retired & $1.9(1.3$ to 2.9$)$ & 3.1 (2.1 to 4.8$)$ & 4.2 (2.8 to 6.2$)$ & $2.0(1.3$ to 3.1$)$ & $2.2(1.4$ to 3.2$)$ & $0.6(0.4$ to 1.0$)$ \\
\hline Age & $0.97(0.97$ to 0.98$)$ & $0.98(0.97$ to 0.98$)$ & 1.04 (1.03 to 1.04$)$ & $1.03(1.02$ to 1.05$)$ & 1.07 (1.05 to 1.08$)$ & $1.06(1.05$ to 1.07$)$ \\
\hline
\end{tabular}

teachers statistically were less likely than male farmers to be current smokers.

With one exception, the estimated associations between smoking behaviour and the other three knowledge variables- assessed using six separate backward MIMIC models (three for men and three for women)—were not statistically significant, and the point estimates all shifted toward the null (ie, $\mathrm{OR}=1.0$ ). The statistically significant difference in knowledge about lung

Table 3 Comparison of demographic characteristics and knowledge about tobacco smoking between individuals with different smoking status among 6651 female respondents to the GATS China survey

\begin{tabular}{|c|c|c|c|c|c|c|}
\hline \multirow{2}{*}{ Variable } & \multicolumn{2}{|c|}{ Never versus current smokers } & \multicolumn{2}{|c|}{ Past versus current smokers } & \multicolumn{2}{|c|}{ Past versus never smokers } \\
\hline & uOR $(95 \% \mathrm{Cl})$ & aOR $(95 \% \mathrm{Cl})$ & uOR $(95 \% \mathrm{Cl})$ & aOR $(95 \% \mathrm{Cl})$ & uOR $(95 \% \mathrm{Cl})$ & aOR $(95 \% \mathrm{Cl})$ \\
\hline \multicolumn{7}{|l|}{ Knowledge } \\
\hline Smoking causes lung cancer & $2.8(1.8$ to 4.4$)$ & $1.9(1.2$ to 2.8$)$ & $1.5(0.8$ to 2.7$)$ & $1.4(0.7$ to 3.0$)$ & $0.5(0.3$ to 1.1$)$ & 0.7 (0.4 to 1.6$)$ \\
\hline Smoking causes heart attack & $1.8(1.0$ to 3.1$)$ & $1.5(0.7$ to 2.9$)$ & $2.2(1.1$ to 4.7$)$ & $3.1(1.0$ to 9.9$)$ & $1.2(0.6$ to 2.6$)$ & 2.1 (0.8 to 5.6$)$ \\
\hline Smoking causes stroke & $1.3(0.8$ to 2.0$)$ & 0.7 (0.4 to 1.2$)$ & $1.0(0.6$ to 1.7$)$ & $0.4(0.2$ to 0.9$)$ & $0.8(0.4$ to 1.6$)$ & $0.6(0.3$ to 1.2$)$ \\
\hline Low-tar cigarettes not less harmful & $4.2(2.0$ to 8.8$)$ & $2.9(1.3$ to 6.6$)$ & $5.1(1.4$ to 18.1$)$ & 5.5 (1.3 to 23.2$)$ & $1.2(0.4$ to 3.3$)$ & $1.9(0.7$ to 5.4$)$ \\
\hline Urban residence & $1.0(0.6$ to 1.6$)$ & $1.3(0.7$ to 2.4$)$ & $0.5(0.3$ to 1.1$)$ & $0.6(0.3$ to 1.3$)$ & $0.5(0.3$ to 1.0$)$ & $0.5(0.2$ to 0.9$)$ \\
\hline \multicolumn{7}{|l|}{ Level of education } \\
\hline No education & 1.0 & 1.0 & 1.0 & 1.0 & 1.0 & 1.0 \\
\hline Primary & 1.3 (0.8 to 2.3 ) & 0.7 (0.4 to 1.3$)$ & 0.7 (0.3 to 1.4$)$ & 0.7 (0.3 to 1.6$)$ & $0.5(0.3$ to 1.0$)$ & $1.0(0.5$ to 1.9$)$ \\
\hline Secondary & 3.1 (1.6 to 6.2$)$ & $1.0(0.5$ to 2.0$)$ & $0.5(0.2$ to 1.3$)$ & $0.6(0.2$ to 1.5$)$ & $0.2(0.1$ to 0.4$)$ & $0.6(0.2$ to 1.5$)$ \\
\hline High school & $3.6(1.5$ to 8.7$)$ & 1.0 (0.4 to 2.5$)$ & $0.5(0.1$ to 2.3$)$ & $0.6(0.1$ to 3.5$)$ & $0.2(0.1$ to 0.4$)$ & $0.6(0.2$ to 2.3$)$ \\
\hline College & $4.1(1.4$ to 12.0$)$ & $0.9(0.2$ to 3.4$)$ & $0.6(0.1$ to 3.3$)$ & $1.0(0.1$ to 10.8$)$ & $0.1(<0.1$ to 0.5$)$ & $1.2(0.2$ to 7.4$)$ \\
\hline \multicolumn{7}{|l|}{ Employment* } \\
\hline Farmer & 1.0 & 1.0 & 1.0 & 1.0 & 1.0 & 1.0 \\
\hline Factory worker/soldier & $2.2(1.0$ to 5.1$)$ & $1.1(0.5$ to 2.7$)$ & 1.1 (0.3 to 3.8$)$ & $1.1(0.3$ to 4.1$)$ & $0.5(0.2$ to 1.4$)$ & $1.0(0.3$ to 2.8$)$ \\
\hline Unemployed & $0.9(0.5$ to 1.9$)$ & 0.9 (0.4 to 2.0$)$ & 1.7 (0.9 to 3.4$)$ & 1.1 (0.6 to 2.3 ) & $1.8(0.8$ to 4.4$)$ & 1.3 (0.6 to 3.0$)$ \\
\hline Retired & 0.9 (0.4 to 1.9$)$ & 1.3 (0.5 to 3.2$)$ & 1.7 (0.6 to 4.7$)$ & 0.8 (0.2 to 2.5$)$ & $1.9(0.6$ to 6.0$)$ & $0.6(0.2$ to 2.0$)$ \\
\hline Age & $0.96(0.95$ to 0.97$)$ & $0.96(0.950 .97)$ & 1.03 (1.01 to 1.05$)$ & 1.02 (1.00 to 1.04$)$ & 1.07 (1.05 to 1.09$)$ & 1.06 (1.04 to 1.08$)$ \\
\hline
\end{tabular}


Table 4 Relationship of smoking status to knowledge about low-tar cigarettes in 6603 male and 6751 female respondents to the GATS China survey using a structural equation modelling approach that adjusts for general knowledge about smoking using a latent variable*

\begin{tabular}{|c|c|c|c|}
\hline & Never versus current smokers & Past versus current smokers & Past versus never smokers \\
\hline \multicolumn{4}{|l|}{ Male respondents } \\
\hline Latent knowledge & $1.2(1.1$ to 1.3$)$ & $1.3(1.1$ to 1.6$)$ & $1.1(0.9$ to 1.3$)$ \\
\hline Low-tar cigarettes not less harmful & 1.3 (1.0 to 1.7$)$ & $2.1(1.5$ to 3.0$)$ & $1.6(1.1$ to 2.3$)$ \\
\hline Urban residence & $1.0(0.8$ to 1.3$)$ & 1.1 (0.8 to 1.6$)$ & $1.1(0.7$ to 1.7$)$ \\
\hline \multicolumn{4}{|l|}{ Level of education } \\
\hline No education & 1.0 & 1.0 & 1.0 \\
\hline Primary & $0.8(0.5$ to 1.3$)$ & $1.2(0.8$ to 1.7$)$ & $1.5(0.8$ to 2.9$)$ \\
\hline Secondary & 0.7 (0.4 to 1.1$)$ & $0.8(0.5$ to 1.3$)$ & $1.1(0.2$ to 2.4$)$ \\
\hline High school & $0.6(0.4$ to 1.0$)$ & 1.0 (0.6 to 1.6$)$ & 1.6 (0.6 to 3.3 ) \\
\hline College & 1.2 (0.6 to 2.3 ) & $0.9(0.5$ to 1.7$)$ & 0.7 (0.3 to 1.6$)$ \\
\hline \multicolumn{4}{|l|}{ Employment } \\
\hline Farmer & 1.0 & 1.0 & 1.0 \\
\hline Factory worker/soldier & $1.2(0.9$ to 1.7$)$ & $1.3(0.8$ to 2.1$)$ & 1.0 (0.6 to 1.6$)$ \\
\hline Office worker & $1.2(0.9$ to 1.7$)$ & $1.2(0.8$ to 1.7$)$ & $1.0(0.6$ to 1.6$)$ \\
\hline Doctor/teacher & 2.2 (1.3 to 3.6$)$ & 1.8 (0.9 to 3.9$)$ & 0.7 (0.2 to 2.4$)$ \\
\hline Unemployed & $1.5(1.0$ to 2.1$)$ & $3.0(1.8$ to 4.8$)$ & $2.0(1.2$ to 3.2$)$ \\
\hline Retired & $4.0(2.6$ to 6.1$)$ & $2.6(1.6$ to 4.4$)$ & 0.7 (0.4 to 1.1$)$ \\
\hline Age & $0.98(0.97$ to 0.98$)$ & $1.03(1.02$ to 1.04$)$ & $1.06(1.05$ to 1.07$)$ \\
\hline \multicolumn{4}{|l|}{ Female respondents } \\
\hline Latent knowledge & $1.4(1.0$ to 1.9$)$ & 1.5 (1.0 to 2.2$)$ & 1.1 (0.7 to 1.6$)$ \\
\hline Low-tar cigarettes not less harmful & $2.8(1.3$ to 5.9$)$ & $5.0(1.3$ to 20.1$)$ & $1.8(0.6$ to 5.2$)$ \\
\hline Urban residence & 1.2 (0.6 to 2.4$)$ & $0.6(0.3$ to 1.3$)$ & $0.5(0.2$ to 0.9$)$ \\
\hline \multicolumn{4}{|l|}{ Level of education } \\
\hline No education & 1.0 & 1.0 & 1.0 \\
\hline Primary & $0.8(0.4$ to 1.3$)$ & 0.7 (0.3 to 1.6$)$ & $0.9(0.5$ to 1.9$)$ \\
\hline Secondary & $1.0(0.5$ to 2.1$)$ & $0.6(0.2$ to 1.6$)$ & 0.6 (0.2 to 1.5$)$ \\
\hline High school & 1.2 (0.5 to 2.7 ) & 0.6 (0.1 to 3.4) & $0.6(0.1$ to 2.1$)$ \\
\hline College & 1.2 (0.3 to 4.3$)$ & 0.9 (0.1 to 8.6) & 0.8 (0.1 to 4.5$)$ \\
\hline \multicolumn{4}{|l|}{ Employment† } \\
\hline Farmer & 1.0 & 1.0 & 1.0 \\
\hline Factory worker & 1.1 (0.5 to 2.4 ) & 1.2 (0.4 to 3.9$)$ & 0.8 (0.3 to 2.5$)$ \\
\hline Unemployed & 0.8 (0.4 to 1.9$)$ & $1.2(0.6$ to 2.4$)$ & $1.3(0.4$ to 4.5$)$ \\
\hline Retired & 1.2 (0.5 to 2.9$)$ & 0.8 (0.3 to 2.3$)$ & 0.6 (0.2 to 2.2$)$ \\
\hline Age & 0.96 (0.95 to 0.97$)$ & $1.02(1.00$ to 1.04$)$ & 1.06 (1.04 to 1.08$)$ \\
\hline
\end{tabular}

cancer between never and current female smokers in multinomial logistic regression $(\mathrm{OR}=1.9)$ became statistically insignificant after the latent level of knowledge was accounted for $(\mathrm{OR}=1.2$, 95\% CI 0.8 to 1.9$)$. Similarly, the significant difference in knowledge about the relationship of heart attack to smoking between past and current female smokers became statistically insignificant after adjustment for latent level of knowledge (OR changed from 3.1 to 1.2 ).

The exception was that, in female respondents, the inverse association between smoking status and knowledge about the role of smoking in stroke remained robust (tables 2 and 3). Women who had ceased smoking were less likely to know about the role of smoking in stroke than current female smokers $(\mathrm{OR}=0.5,95 \%$ CI 0.3 to 0.9$)$; women who had never smoked were less likely than current female smokers to know of the relationship of smoking to stroke $(\mathrm{OR}=0.7,95 \% \mathrm{CI} 0.4$ to 1.0 , trend only). That is, current female smokers were more likely to respond correctly to the question about the role of smoking as a cause of stroke than the other two groups of women.

\section{DISCUSSION}

The main findings of this study can be summarised as follows. First, the misconception that 'low-tar cigarettes are less harmful' is highly prevalent, especially among current smokers. Second, the association between knowledge about the harm of smoking and smoking status varies depending on the specific item of knowledge being considered; the most robust associations with smoking status were those found for the knowledge about the harmful effects of low-tar cigarettes. Third, stronger associations between knowledge and smoking status were observed among women than men. Finally, men who were out of the workforce were more likely to cease smoking.

Several important study limitations merit attention. The study is cross-sectional in design, so no causal relationships can be inferred. Given the common fluctuations of current smoking status among smokers who are trying to stop, ${ }^{30}$ the status identified at the time of the survey may not be stable. The use of selfreport information may lead to under-reporting of current and past smoking; however, studies from elsewhere confirm the 
validity of self-reports of smoking status. ${ }^{31} 32$ Several other variables related to smoking behaviour have not been considered (eg, economic status, family influences). Furthermore, other aspects of smoking-related knowledge were not assessed, so it is possible that the latent knowledge variable used in our analysis may not perfectly capture the level of smoking-related knowledge. However, previous studies have found that knowledge about the relationship of smoking to serious disease is the most relevant to smoking behaviour. ${ }^{13} 20$ Finally, the much smaller number of current and past female smokers than male smokers meant that much larger ORs were needed to meet conventional levels of statistical significance in women than men. The small number of female smokers also precluded precise estimates for the association between smoking status and some employment categories.

Counterbalancing strengths of this study include (1) a clearly predefined source population-household-dwelling residents of China who were at least 15 years of age (the population among whom the vast majority of smoking-related disease burden resides); (2) a large, representative sample; and (3) adjustment for multiple variables about smoking-related knowledge and construction of the latent knowledge variable, which enabled the study to identify the specific knowledge variable that is most important for tobacco control.

Findings from this study provide supporting evidence for the role of knowledge about low-tar cigarettes in smoking control, which is in line with previous findings from the USA. ${ }^{33}$ In this study, male smokers who knew low-tar cigarettes were not less harmful were twice as likely to quit than those who did not know the dangers of low-tar cigarettes; and female smokers who knew this were fivefold more likely to quit. Moreover, current female smokers were much less likely to know about low-tar cigarettes than women who had never started smoking.

Studies on the toxicity of low-tar cigarettes and the smoking patterns of those who smoke low-tar cigarettes increase the urgency of this issue. Reports from China indicate that Chinese cigarettes labelled 'low-tar' deliver no less carcinogen or nicotine than their regular counterparts. In fact, there was a nonsignificant trend $(p=0.053)$ for increased levels of these nicotine metabolites and carcinogens among low-tar cigarette smokers than in regular cigarette smokers after adjustment for total cigarette consumption. ${ }^{34}$ Paired with the body of literature on the larger consumption and deeper inhalation among smokers of low-tar cigarettes, these findings suggest that, in China, the latter are at higher risk of negative health outcomes than those who smoke regular cigarettes.

Perhaps more important from a policy perspective, less than $15 \%$ of adults in China know about the health risks of low-tar cigarettes. ${ }^{2}$ Tobacco companies had been promoting low-tar cigarettes as a 'healthier' alternative in China before this practice was banned in 2006. There are no national-level data about the awareness of the risk of low-tar cigarettes before the 2006 ban on this type of advertising that would indicate whether or not the ban resulted in changes in community awareness, but evidence from the $\mathrm{UK}^{35}$ suggests that such bans do little to change current levels of knowledge about the risks of smoking. Thus, policies and public education should go beyond the mere banning of misleading advertising by tobacco companies; they must actively promulgate correct information to the community as a whole.

Surprisingly, women who were current smokers were significantly more likely to know that smoking was a cause of stroke than women who had ceased or never started to smoke. Subgroup analysis found that that this inverse association only exists among women who also knew that smoking causes heart attack; there is no relationship between smoking status and knowledge about the role of smoking in stroke among women who do not know that smoking causes heart attacks. To date, social disapproval of women who smoke has kept smoking rates among women in China quite low. ${ }^{3}$ Thus, women have to break a strong social barrier to become smokers. Knowing that smoking causes both heart attacks and stroke may be more common in women who choose to break this social barrier to become regular smokers; and once the barrier is broken, they may be less likely to quit smoking than female smokers who do not know that smoking causes both stroke and heart attacks. Future research about the characteristics of women who breach this social norm is needed to understand this unexpected observation and, more importantly, to identify policies or other initiatives that will make it even more difficult for women to cross this threshold.

The occupational profile of smokers in China identified in this study appears to differ from the conventional wisdom that 'blue collar' workers are more likely to be smokers. ${ }^{15} 3637$ The most striking finding is that doctors and teachers were not less likely to quit smoking once they started. In contrast with conventional wisdom, men who were out of the workforce, either through unemployment or retirement, were more likely to cease smoking. Although the present study is not able to infer causality, this finding suggests that workplace smoking is well tolerated in China. Among men of all social strata in China, offering others cigarettes is an extremely common way to help build, maintain or reinforce relationships. This finding highlights the importance of work-related smoking in China and, possibly, in other countries where collectivism remains a core societal value. Clearly, this needs to be an important focus for intervention activities.

Longitudinal studies of large representative samples of community members are needed to confirm these findings. Given the poor results of public education initiatives and intervention programmes to date and the very real danger of repeating the male smoking epidemic in women in China, there is an urgent need to use innovative analytical techniques (such as the latent variable analysis used in this study) to develop improved models for understanding the dynamic relationship between knowledge about the risks of smoking and smoking behaviour. These models could then be used to develop and test innovative methods for addressing this important public health problem both in China and elsewhere.

\section{What this paper adds}

- After the general level of smoking-related knowledge is controlled for, knowing that low-tar cigarettes are not less harmful is associated with smoking cessation in China.

- Working Chinese men are more likely to smoke whatever the nature of their jobs (eg, 'white collar' or 'blue collar').

- The structural equation modelling approach provides a viable way to control for the intercorrelation between knowledge variables in tobacco research.

Acknowledgements The authors wish to thank the GATS China group for their efforts to make the data publicly available.

Contributors HGC and OM designed the analytical strategies. HGC carried out data analysis and wrote the first draft of the manuscript. OM and MRP participated in interpretation of the data and provided critical revisions to the manuscript. All authors contributed to and approved the paper. 
Competing interests None.

Provenance and peer review Not commissioned; externally peer reviewed.

Open Access This is an Open Access article distributed in accordance with the Creative Commons Attribution Non Commercial (CC BY-NC 3.0) license, which permits others to distribute, remix, adapt, build upon this work non-commercially, and license their derivative works on different terms, provided the original work is properly cited and the use is non-commercial. See: http://creativecommons.org/ licenses/by-nc/3.0/

\section{REFERENCES}

1 Murray CJ, Lopez AD. Alternative projections of mortality and disability by cause 1990-2020: global burden of disease study. Lancet 1997;349:1498-504.

2 Li Q, Hsia J, Yang G. Prevalence of smoking in China in 2010. NEJM 2011;364:2469-70.

3 Storr $\mathrm{CL}$, Cheng $\mathrm{H}$, Alonso J, et al. Smoking estimates from around the world: data from the first 17 participating countries in the World Mental Health survey consortium. Tob Control 2010;19:65-74.

4 Ward MM, Vaughn TE, Uden-Holman T, et al. Physician knowledge, attitudes and practices regarding a widely implemented guideline. J Eval Clin Pract 2002;8:155-62.

5 Finney Rutten L, Augustson EM, Moser RP, et al. Smoking knowledge and behavior in the United States: sociodemographic, smoking status, and geographic patterns. Nicotine Tob Res 2008;10:1559-70.

6 Nobile CG, Anfosso R, Pavia M, et al. Cigarette smoking: knowledge, attitudes and behaviour in an adult population in Italy. Public Health 2000;114:348-52.

7 Han MY, Chen WQ, Chen X. Do smoking knowledge, attitudes and behaviors change with years of schooling? A comparison of medical with non-medical students in China. J Community Health 2011;36:966-74.

8 Lin YS, Wu DM, Lai HR, et al. Influence of knowledge and attitudes on smoking habits among young military conscripts in Taiwan. J Chin Med Assoc 2010;73:411-18.

9 Klink K, Lin S, Elkin Z, et al. Smoking cessation knowledge, attitudes, and practice among community health providers in China. Fam Med 2011;43:198-200.

10 Wen X, Chen W, Qian Z, et al. Differences in students' smoking-related knowledge, attitudes, and behaviors among public, factory, and private secondary schools in Guangzhou, China. J Sch Health 2008;78:46-53.

11 Yang GH, Li Q, Wang CX, et al. Findings from 2010 Global Adult Tobacco Survey: implementation of MPOWER policy in China. Biomed Environ Sci 2010;23:422-9.

12 Jiang $Y$, Ong MK, Tong EK, et al. Chinese physicians and their smoking knowledge, attitudes, and practices. Am J Prev Med 2007;33:15-22.

13 Minh An DT, Van Minh H, Huong le T, et al. Knowledge of the health consequences of tobacco smoking: a cross-sectional survey of Vietnamese adults. Glob Health Action 2013;6:1-9.

14 Ding D, Hovell MF, Ji M, et al. Employment and social "determinants" of smoking in urbanizing China: a representative survey. Nicotine Tob Res 2009;11:779-84.

15 Smith DR. Tobacco smoking by occupation in Australia and the United States: a review of national surveys conducted between 1970 and 2005. Ind Health 2008;46:77-89.

16 Yang G, Fan L, Tan J, et al. Smoking in China: findings of the 1996 National Prevalence Survey. JAMA 1999;282:1247-53.

17 Reimer RA, Gerrard M, Gibbons FX. Racial disparities in smoking knowledge among current smokers: data from the health information national trends surveys. Psychol Health 2010;25:943-59.
18 Nishi N, Ogurii S, Onoda T, et al. Knowledge of smoking-related risks and opinions on tobacco control by smoking status and education level in Japan. Nihon Koshu Eisei Zasshi 2005;52:962-70.

19 Liang KY, Zeger SL. Regression analysis for correlated data. Annu Rev Public Health 1993;14:43-68.

20 Constantine ML, Rockwood TH, Schillo BA, et al. The relationship between acculturation and knowledge of health harms and benefits associated with smoking in the Latino population of Minnesota. Addict Behav 2009:34:980-3.

21 Walther CA, Cheong J, Molina BS, et al. Substance use and delinquency among adolescents with childhood ADHD: the protective role of parenting. Psychol Addict Behav. 2012;26:585-98.

22 Hecht SS, Murphy SE, Carmella SG, et al. Similar uptake of lung carcinogens by smokers of regular, light, and ultralight cigarettes. Cancer Epidemiol Biomarkers Prev 2005;14:693-8.

23 GATS China Workgroup. Yang G, ed. Global Adult Tobacco Survey (GATS) China 2010 Country Report. Geneva: WHO, 2010:1-205.

24 Muthén BO. Latent variable modeling in epidemiology. Alcohol Health Res World 1992;24:286-92.

25 Jöreskog KG, Sörbom D. Advances in factor analysis and structural equation models. Cambridge, MA: Abt Books, 1979.

26 Muthén BO. A structural model with latent variables. J Amer Stat Assoc 1979;74:807-11.

27 Cheng $\mathrm{HG}$, Anthony JC, Huang Y, et al. Childhood physical punishment and the onset of drinking problems: evidence from metropolitan China. Drug Alcohol Depend 2011;118:31-9.

28 Cheng HG, Anthony JC, Huang Y. Harsh physical punishment as a specific childhood adversity linked to adult drinking consequences: evidence from China. Addiction 2010;105:2097-105.

29 GATS Group. Global Adult Tobacco Survey (GATS): Sample Weights Manual, Version 2.0. Atlanta, GA: Centers for Disease Control and Prevention, 2010.

30 Hughes JR, Solomon LJ, Fingar JR, et al. The natural history of efforts to stop smoking: a prospective cohort study. Drug Alcohol Depend 2013;128:171-4.

31 Yeager DS, Krosnick JA. The validity of self-reported nicotine product use in the 2001-2008 National Health and Nutrition Examination Survey. Med Care 2010;48:1128-32.

32 Murray RP, Connett JE, Lauger GG, et al. Error in smoking measures: effects of intervention on relations of cotinine and carbon monoxide to self-reported smoking. The Lung Health Study Research Group. Am I Public Health 1993:83:1251-7.

33 Gilpin EA, Emery S, White MM, et al. Does tobacco industry marketing of 'light' cigarettes give smokers a rationale for postponing quitting? Nicotine Tob Res 2002;4(Suppl 2):S147-155.

34 Gan Q, Lu W, Xu J, et al. Chinese 'low-tar' cigarettes do not deliver lower levels of nicotine and carcinogens. Tob Control 2010;19(5):374-379.

35 Borland R, Fong GT, Yong HH, et al. What happened to smokers' beliefs about light cigarettes when "light/mild" brand descriptors were banned in the UK? Findings from the International Tobacco Control (ITC) Four Country Survey. Tob Control 2008;17: 256-62.

36 Bang KM, Kim JH. Prevalence of cigarette smoking by occupation and industry in the United States. Am I Ind Med 2001;40:233-9.

37 Siahpush M, Heller G, Singh G. Lower levels of occupation, income and education are strongly associated with a longer smoking duration: multivariate results from the 2001 Australian national drug strategy survey. Public Health 2005;119:1105-10. 